\title{
Research of University Examination Reform under the Concept of Innovative Talent Cultivation
}

\author{
Baohua Cui \\ Economic Management Department, Jilin Agricultural University, \\ Changchun, China \\ Email: cbhjlau@yeah.net
}

Keywords: innovative; talent cultivation; examination reform

\begin{abstract}
The paper explores and systematically analyzes the restriction and influence of examination on talent cultivation and selection by dis-secting the defects existing in high school examinations, and puts forward an original point of view on how to reform examination in schools to cultivate talents.
\end{abstract}

\section{Introduction}

The development of the knowledge economy needs innovative talents. The cultivation of university innovative talents which concerns overall situation of modernization has become an important strategic task of the world higher education. Examination and examination evaluation system are indispensable for the cultivation of innovative talents. Examination is very important in the teaching process and is the key to the process of teaching and an important starting point for teaching evaluation. In the teaching process, the exact application of this tool can help teachers evaluate teaching result effectively and maser the teaching situation timely and improve the pertinency of teaching and studying. The university examination evaluation system is the guidance for teaching and studying and it is also a double-edged sword. An excellent examination evaluation system can propel and accelerate the cultivation of innovative talents. Otherwise, the unreasonable one will be obstacle for cultivating innovative talents.

\section{The relation between examination and the cultivation of innovative talents}

\section{The cultivation of innovative talents is the main objective of higher education.}

Knowledge innovation is the important feature of knowledge economy and it is also the only driving force for the social development in the knowledge economy era. The central power of knowledge innovation is innovative talents who are capable of exploring the changing rules of human society and nature with scientific attitude on the basis of needs of era development and who are brave to reform the old things and create new ones. The cultivation and development of innovative talent is a system project which needs the whole society to work together to achieve. However, there is no doubt that education is the source of cultivating innovative talents. If the primary and secondary education is the teaching and spreading of the knowledge that humans have created, then higher education should be able to cultivate innovative talents who can create new knowledge. Therefore, cultivating innovative talents is the primary goal of higher education, which is the highest requirement of society to university to cultivate talents ${ }^{[1]}$.

\section{Examination evaluation has an important role in the process of cultivating innovative} talents.

Examination is a key section in the educational process and an important means to achieve the evaluation of teaching effectiveness and the insurance of education and teaching activities. The effect of examination on personnel training is objective. Reasonable and scientific exam possesses the function of diagnosis, improvement, guidance, evaluation and study. The first one is diagnosis: teachers can understand the present situation through examination and strengthen the pertinence of teaching and learning. The second one is improvement: it can help teachers and students constantly 
improve and perfect the action by using the principle of feedback. The third one is guidance: the content and evaluation criteria of examination decide the direction of student effort, the learning focus, and the distribution of learning power. The fourth one is evaluation: examination results can identify and determine the qualification of the students' learning outcomes, the degree of judgment, the level and other actual value of the effectiveness and capacity. The last is study: the preparation and participation in examination is also a kind of learning and an essential part of teaching. Only with the scientific examination and the consistence of examination purpose, content, forms, methods and the requirement and purpose of cultivating university innovative talents, can it be fostered to cultivate innovative talents with comprehensive development for universities ${ }^{[2]}$.

\section{Analysis on problems existing in traditional test method}

Too single exam means.

In the traditional exam, closed book, open-book, essay writing and understanding of the experimental operation are the main forms, and in these forms, the closed-book exam is often used, other forms are not usually used. Meanwhile, the exam contents focus on theory and knowledge and limit to textbooks and most teachers will circle the exam scope and five the main focus. And in fact, this assessment method does not assess a student's real learning ability and is also bound to seriously mislead students' usual study making them think they should only learn the contents in the textbook. Many students consider not how to effectively understand and master the knowledge and improve their quality and ability but the exam grades. It is difficult for exam to achieve the transition from teacher's "teaching" to student's independent "learning". It is also difficult to play the role of cultivating students' innovation capacity and improving their overall quality.

\section{Too concentrated exam time.}

Freshman and sophomore learn basic courses and the exams of most basic classes are arranged in the end of the term. Because of the need to participate in curriculum design, graduation design, production practice, etc., juniors and seniors have to experience the examination time conflict, which has resulted in students' being under immense pressure of examinations in a short time and led to the students' being slack at the beginning and have to speed up towards the end. It is not conducive to the rational allocation of study time and students cannot consolidate the learning outcomes timely. Except for bad exam result, it is also extremely unfavorable for students' physical and mental health ${ }^{[3]}$.

\section{Too single test content and scoring method.}

Now most of the content of college examination is still focused on the understanding, master, or simple application of basic knowledge, basic theory, and basic skills and ignore the detection of the ability, quality, and innovation factors. On the scoring mode, answers standardization is focused and the instructor must be accompanied by the standard answer when designing the test which lacks heterosexual and innovation consciousness. The biggest drawback of this kind of exam and scoring method is its influence on the quality of personnel training, especially the unfavorable influence on the cultivation of innovative talents. It confined the teaching and learning activities to the understanding and master of basic knowledge, basic theory, and basic skills and did not embody the exploratory, researching and innovative features of higher education, which led to the talents cultivated are still lack ability and innovation and with poor comprehensive quality who cannot adapt to the requirement of era development.

\section{Deepening the reform of the examination in colleges and universities}

Scientific examination evaluation system and standard management is the foundation of the school to survive and develop. The cultivation of innovative talents needs more scientific examination evaluation system to be guaranteed. The training of students' innovative spirit is key points and difficulties of the current examination system reform. It is pointed in "The decision of the state council of the central committee of the communist party of China on deepening education reform and comprehensively promote quality education" that the focus of the reform of exam 
content should be to examine the students' problem-analyzing ability, problem-solving ability and creativity by utilizing knowledge $\mathrm{e}^{[4]}$.

\section{Content and form of innovation test.}

The exam is to serve the purpose of cultivating innovative talents. On the one hand, examination content should be combined with characteristics of subject to design different content and implement individualized evaluation principle. On the other hand, the test content should reflect temporal spirit and innovation which should assess both students' knowledge level and students' ability to apply knowledge to solve practical problems and their creative thinking ability. The test content should be challenging and competitive and can fully stimulate students' innovation consciousness and passion. Creative and innovative answers should be encouraged by adding grades to guide and cultivate students' innovative thinking. In addition, the scientification and diversification of test form are also essential. Test way should be flexible and the test on theory and knowledge should be combined with the test on innovative factors. The examination can be aim to either some aspect or comprehensive aspect and aim to either individual student or all students. In the usual teaching, experiment, practice, science and technology activities and social practice, the test should be dispersive and there is no need to make intensive exam at the end of the semester.

\section{Adopt multiple evaluation model.}

Adopt different evaluation ways on the innovative talent training According to the requirements of different courses, especially to draw lessons from foreign evaluation methods. Take students' ability to analyze problems, solve the problem and the students' practical ability and innovation ability as the standard of teaching evaluation. Strengthen the proportion of usual grades in overall grades and combine the process evaluation with summative evaluation and penetrate evaluation throughout the whole process of classroom teaching. In this way, students' enthusiasm and initiative can be motivated and this evaluation is the comprehensive examination of non-intelligence factors such as students' learning attitude, which promote students to form correct world outlook and correct outlook on life and values while mastering the knowledge and skills.

\section{Perfect the examination management system.}

Gradually promote teaching and examination separation system and strict examination quality analysis evaluation. The practice of teaching-examination separation and the promotion of diversification of the evaluation can ensure the scientific nature of the evaluation results, motivate students to learn, and improve the teaching quality. Establish a system for testing credit and reduce the possibility of cheating in the exam. The foundation of reducing the possibility of cheating in the exam is to solve the minority college students' honesty crisis. Schools should strengthen the integrity of moral education and establish student credit system. Establish credit files for each of the students and relate cheating in the exam with individual integrity character to make credit archives and academic records having the same credibility ${ }^{[5]}$.

\section{Improve the quality of the teachers' education evaluation.}

Teachers are in a dominant position in teaching and whether the examination reform can be successfully implemented or not lies in teachers. Only teachers with innovative awareness and ability to implement innovation education, can students' innovative consciousness and innovative ability be cultivated. For this purpose, schools should actively encourage teachers to continue learning, refresher training and to participate in academic exchanges, in order to make the academic level of teachers' professional knowledge and can have larger breakthrough. Teachers need to consciously learn some theory knowledge about education measure and improve their theory quality to guarantee the quality of the test and the fairness of the exam which is in the charge of the teachers. 


\section{Conclusion}

So far, the advanced concept of establishing and perfecting education examination evaluation system from single exam to multiple evaluation influences people gradually and has become the direction of the examination and evaluation system reform and the catalyst of education reform development. However, in order to transform the advanced ideas, thoughts into concrete practice procedures, ways and means, we still need to unswervingly shoulder the historical mission of building an innovation-oriented country and innovative education and cultivating creative talents in accordance with the requirements of the scientific concept of development. The new era have entrusted us the historical mission that stepping forward to the goal of the reform development of examination and evaluation.

\section{References}

[1] Qin Gangnian. Innovative talents cultivation and construction of experimental teaching demonstration center. [J]. Research and Exploration in Laboratory, 2010,29(7).

[2] Qin Weilin, Zhou Xiaoguang. Exploration on examination reform in colleges and universities based on the innovative talent training, [J]. Forestry Education In China, 2013,(10).

[3] Wu Meng, Zhang Xiaoyuan. Examination reform and innovation ability training in colleges and universities. [J]. Modern Enterprise Education, 2013,(8).

[4] He Yunpeng. Discussion on universities examination system reform under the background of quality education. [J]. Education Forum, 2013,(52) .

[5] Duan Huijuan. Universities examination reform under the perspective of innovative talent training. [J]. Market weekly, 2013,(7). 